
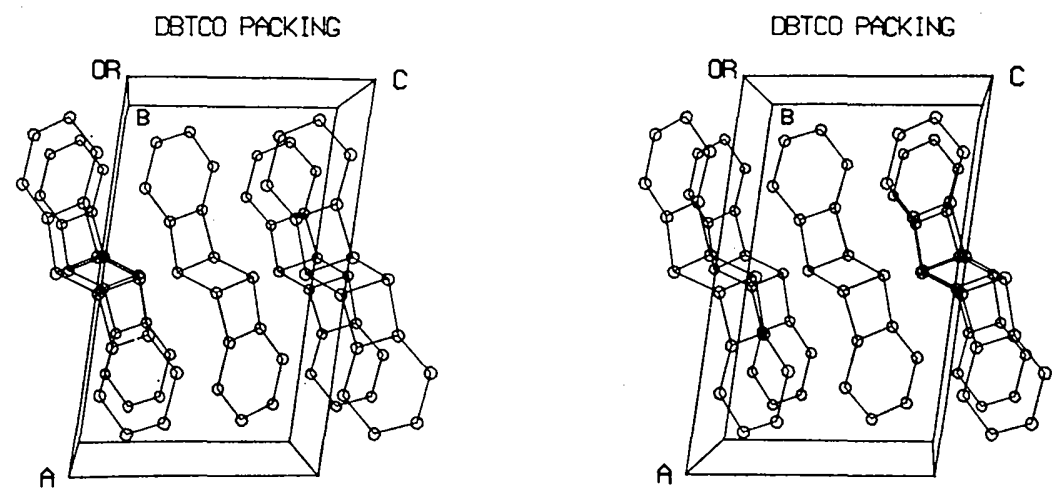

Fig.4. Stereoscopic packing diagram. One unit cell is outlined.

Cava, M. P. \& Napier, D. R. (1957). J. Amer. Chem. Soc. 79, 1701.

Camerman, N. \& Nyburg, S. C. (1969). Acta Cryst. B25, 388.

Camerman, N., Weinblum, D. \& Nyburg, S. C. (1969). J. Amer. Chem. Soc. 91, 982.

Cromer, D. T. \& Waber, J. T. (1965). Acta Cryst. 18, 104.

Dunitz, J. D. \& Schomaker, V. (1952). J. Chem. Phys. 20, 1703.

EInsteIn, J. R., Hosszu, J. L., Longworth, J. L., RahN, R. O. \& WeI, C. H. (1967). Chem. Comm. p. 1063.

Emerson, G. F., Watts, L. \& Pettit, R. (1965). J. Amer. Chem. Soc. 87, 131.

Evans, H. T. (1961). Acta Cryst. 14, 689.
Griffin, G. W. \& Weber, D. F. (1961). Chem. Ind. p. 1162. GVILDYS, J. (1965). Argonne National Laboratory Program B-149.

JoHnson, C. K. (1965). Program ORTEP, ORNL-3794, Revised, Oak Ridge National Laboratory, Oak Ridge, Tennessee.

Karle, J. \& Karle, I. (1969). Acta Cryst. 21, 849.

Kartha, G. (1964). Private communication.

Margulis, T. N. (1965). Acta Cryst. 18, 742.

Silvers, S. \& Tulinsky, A. (1963). Acta Cryst. 16, 579.

Stewart, R. F., Davidson, E. R. \& Simpson, W. T. (1965). J. Chem. Phys. 42, 3175.

Tulinsky, A., Worthington, C. R. \& Pignataro, E. (1959). Acta Cryst. 12, 623.

Acta Cryst. (1970). B26, 1030

\title{
Refinement of the Crystal Structure of Sinigrin*
}

\author{
By Richard E. MARSH AND JÜRG WASER
}

Gates and Noyes Laboratories of Chemistry, California Institute of Technology, Pasadena, California 91109, U.S.A.

(Received 27 May 1969)

\begin{abstract}
The crystal structure of sinigrin (potassium myronate), $\mathrm{KC}_{10} \mathrm{H}_{16} \mathrm{NO}_{9} \mathrm{~S}_{2} . \mathrm{H}_{2} \mathrm{O}$, has been refined on the basis of three-dimensional intensity data collected on an automated diffractometer. The final agreement index is 0.056 for 1906 reflections, and the estimated standard deviations in the atomic coordinates of the $\mathrm{C}, \mathrm{N}$, and $\mathrm{O}$ atoms are about $0.004 \AA$. The absolute configuration of the anion was confirmed from anomalous dispersion effects. The crystals are orthorhombic with space group $P 2_{1} 2_{1} 2_{1}$. The unit-cell dimensions of a new crystal are $a=8.265(1), b=11.440$ (3), and $c=17.757$ (3) $\AA$. An appreciable increase in the length of the $c$ axis occurred during irradiation of the crystal. In addition, the vinyl group of the myronate ion appears to undergo large thermal motions. The distances between vinyl groups of adjacent myronate ions are such that a photopolymerization reaction between them would be possible, which might explain these two observations.
\end{abstract}

The X-ray crystallographic investigation of sinigrin, a salt of the formula $\mathrm{K}^{+}\left(\mathrm{C}_{10} \mathrm{H}_{16} \mathrm{O}_{9} \mathrm{NS}_{2}\right)^{-} \cdot \mathrm{H}_{2} \mathrm{O}$ extracted

* Contribution No. 3857 from the Division of Chemistry and Chemical Engineering, California Institute of Technology. from the seeds of black mustard, was undertaken in the hope of supporting the organic-chemical work of M. Ettlinger and co-workers (Ettlinger \& Lundeen, 1956, 1957; Ettlinger, Dateo, Harrison, Mabry \& Thompson, 1961) on the structure of the anion, also 
called the myronate ion. Fig. 1 shows the chemical formula as well as a structural formula of this ion, the latter based on the results of the X-ray work. The crystal structure was originally worked out from data from isomorphous crystals of potassium, ammonium, and thallium myronate and the results, which confirmed Ettlinger's structure, were briefly reported some years ago (Waser \& Watson, 1963; Waser, 1963). We have recently collected a full set of intensity data on a Datex-automated General Electric diffractometer, on the basis of which we have carried out additional parameter refinement and have confirmed the absolute configuration of the myronate ion. We wish now to report these results.

The sample of sinigrin was obtained from Aldrich Chemical Co., Inc. and was recrystallized from aqueous solution containing a small amount of ethanol. The crystals are orthorhombic, space group $P 2{ }_{1} 2_{1} 2_{1}$<smiles>C=CCC(=NOS([O])([O-])O)SC1C(O)C(O)C(CO)C1O</smiles>

(a)

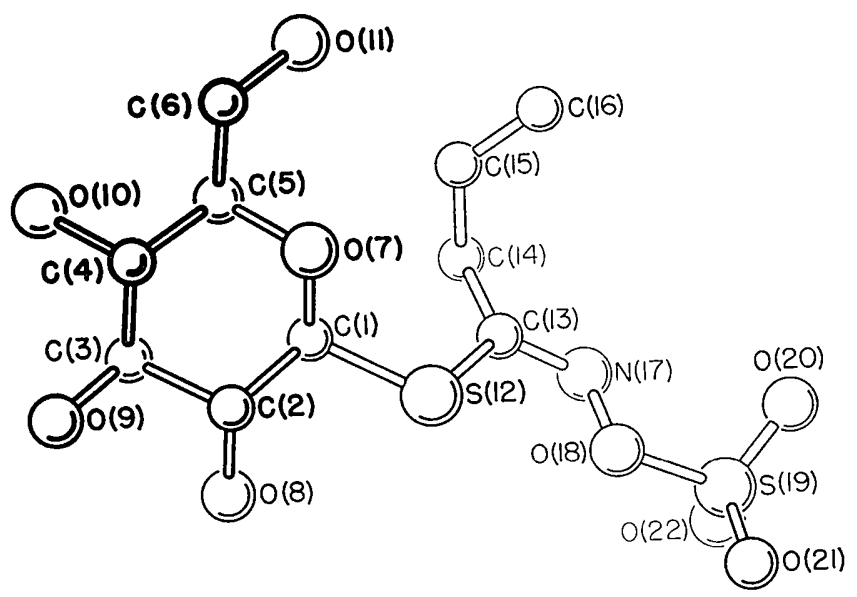

(b)

Fig. 1. (a) Chemical formula and (b) structure of the myronate ion. The structural figure does not show the hydrogen atoms but indicates the numbering of the other atoms; for the numbering of the hydrogen atoms see Table 3 .
( $h 00,0 k 0$, and $00 l$ absent for $h, k$, or $l$ odd). Other crystal data are summarized in Table 1 . The cell dimensions were obtained from high-angle diffractometer data and are based on a wavelength of $1.5418 \AA$ for $\mathrm{Cu} K \alpha$ radiation; the uncertainties given are standard deviations.* The density was measured by flotation.

Table 1. Crystal data

$\begin{array}{ll}\text { Sinigrin (K myronate) } & \mathrm{F} . \mathrm{W} .415 \cdot 48 \\ \mathrm{KC}_{10} \mathrm{H}_{16} \mathrm{O}_{9} \mathrm{NS}_{2} . \mathrm{H}_{2} \mathrm{O} & F(000)=864 \\ \text { Orthorhombic space group } & P 2_{1} 2_{1} 2_{1} \\ & a=8 \cdot 265 \pm 0 \cdot 001 \AA \\ & b=11 \cdot 440 \pm 0 \cdot 003 \\ & c=17 \cdot 757 \pm 0 \cdot 003 \\ & D_{m}=1 \cdot 61(5) \mathrm{g} . \mathrm{cm}^{-3} \\ & D_{x}=1 \cdot 644(1) \\ & V=1679 \AA^{3} \\ & Z=4\end{array}$

The crystal used for measuring intensities was ground to a sphere (Bond, 1951) of diameter $0.209 \mathrm{~mm}$. It was mounted about an arbitrary axis. Intensities were collected, using Ni-filtered $\mathrm{Cu} K \alpha$ radiation, during a $\theta-2 \theta$ scan at a speed of $2^{\circ}$ (in $2 \theta$ ) per minute and over a scan range that varied linearly from $2^{\circ}$ at $2 \theta=20^{\circ}$ to $4^{\circ}$ at $2 \theta=120^{\circ}$; background was collected for 30 seconds at each terminus. Variances in the intensities, $\sigma^{2}(I)$, were obtained from counting statistics with an additional term, $(0 \cdot 02 I)^{2}$, which has seemed appropriate for data collected in these Laboratories. The intensities and their standard deviations were corrected for absorption $(\mu R=0.58)$, Lorentz factor, and polarization effects.

The 008 reflection was checked periodically during the data collection. It showed a continuing drop-off in intensity, linear with exposure time, to a final intensity only slightly greater than $50 \%$ of the starting value. The first 400 reflections were then remeasured; they, too, showed intensities approximately $50 \%$ as great as originally. We were thus encouraged to assume that all reflections were affected equally by radiation damage (or whatever the effect was), and thus to correct all the measurements by an empirical function linear with exposure time. Justification for this procedure ultimately came from the satisfactory match with the measured intensities that we obtained with the final atomic parameters.

A more interesting - and disconcerting - effect of radiation on the crystal was a lengthening of the $c$ axis by an amount that reached nearly $0.2 \AA$. As a result of this lengthening, it was necessary to continually adjust the calculated values of $2 \theta$ to assure capture of the entire diffraction maxima. Possible ramifications of

* The crystals suffered radiation damage, which resulted in a slight yellowing of the crystals and significant changes in the unit-cell dimensions - essentially a lengthening of the $c$ axis by nearly $0 \cdot 2 \AA$ (discussed later). Thus, the cell dimensions we report here apply only to a fresh crystal. 
this effect in terms of the final structure will be discussed later.

All 2045 reflections out to $\sin ^{2} \theta / \lambda^{2}=0.40$ and within the octant $h \leq 0, k$ and $l \geq 0$ were measured. Of these, 135 were indistinguishable from background and were given zero weight. Four additional reflections $-\overline{3}, 1,10$; $\overline{4}, 1,10 ; \overline{5}, 1,10 ; \overline{6}, 1,10$-had recorded intensities less than one-quarter of those calculated from the final parameter set, and were ultimately assigned zero weight also. We do not know why these measurements were low; since the four reflections were measured consecutively, we suspect a temporary failure of the instrumentation.

The starting point for the refinement was the set of parameters obtained from the earlier structure determination based on photographic data (Waser \& Watson, 1963), which included isotropic temperature factors and yielded an $R$ index $\left(R=\sum|| F_{o}|-| F_{c}|| / \sum\left|F_{o}\right|\right)$ of $0 \cdot 16$. All calculations were carried out on an IBM 7094 computer under control of the CRYRM system (Duchamp, 1964). Atomic form factors for $\mathrm{K}^{+}, \mathrm{S}, \mathrm{C}$, $\mathrm{N}$, and $\mathrm{O}$ were taken from International Tables for $X$-ray Crystallography (1962); those for hydrogen were from Stewart, Davidson \& Simpson (1965). The quantity minimized in the least-squares refinement was $\sum w\left[F_{o}^{2}-\left(1 / k^{2}\right) F_{c}^{2}\right]^{2} ; k$ is the scale factor but the parameter refined was $(1 / k)$. The weights $w$ were taken equal to the reciprocals of the experimental variances $\sigma^{2}\left(F_{o}^{2}\right)$.

In nine least-squares cycles the following parameters were gradually added: anisotropic temperature parameters, first for the sulfur atoms and the potassium ion and then for the $\mathrm{C}, \mathrm{N}$, and $\mathrm{O}$ atoms as well; a parameter for secondary extinction (Zachariasen, 1963; Larson, 1967); coordinates of the hydrogen atoms (the starting values having been obtained from considerations of molecular geometry, hydrogen bonding and, in a few ambiguous cases, from a difference Fourier synthesis); and isotropic temperature parameters for the hydrogen atoms. The initial cycles involved two, and later cycles three, complete matrices, the terms relating to the coordinates of the heavier $(\mathrm{K}, \mathrm{S}, \mathrm{C}, \mathrm{N}, \mathrm{O})$ atoms being contained in the first matrix, the temperature parameters of these atoms together with the scale and secondary extinction parameters in the second, and the coordinates and temperature parameters of the hydrogen atoms in the third.

After seven refinement cycles, $R$ had fallen to 0.0592 and the 'goodness of fit', $\left[\sum w\left(F_{o}^{2}-(1 / k)^{2} F_{c}^{2}\right)^{2} /(m-s),\right]^{1 / 2}$ to 1.62 ; all parameters had converged satisfactorily with the exception of those associated with the vinyl group [C(14), C(15), C(16) and their hydrogen atoms] and the hydrogen atoms of the water molecules, which continued to oscillate. In two final cycles these recalcitrant positional and temperature parameters (including those of the oxygen atom of the water molecule) were grouped in one matrix, while a second matrix contained the remaining coordinates and a third matrix the left over temperature coefficients, the scale factor, and the secondary extinction parameter. Convergence was now satisfactory.
Up until now, no particular attention had been paid to the configuration of the molecule; in fact, whereas the intensity data had been obtained from diffraction planes having $h$ negative or zero, $h$ had been assumed to be positive or zero. At this point corrections were made for the anomalous dispersion of the sulfur atoms and the potassium ions. The corrections for the form factors used were $\Delta f_{\mathrm{S}}^{\prime}=0 \cdot 31, \Delta f_{\mathrm{S}}^{\prime \prime}=0 \cdot 58, \Delta f_{\mathrm{K}}^{\prime}=0 \cdot 37$, and $\Delta f_{\mathrm{K}}^{\prime \prime}=1 \cdot 11$, the primed values being real and the doublyprimed values imaginary (Cromer, 1965). The signs of the Miller indices $h$ were reversed and structure factors were calculated both for the set of parameters refined so far and for the set that corresponded to a reflection across the $y z$ plane (for which the signs of the $x$ parameters and the temperature parameters $b_{12}$ and $b_{13}$ were reversed). The first variant yielded $R=0.064$ and a goodness of fit of $1 \cdot 68$, and the second 0.074 and $2 \cdot 12$. (No adjustment for an increase in scale factor $(k)$ of about $2 \cdot 3$ per cent was made in these calculations, which accounts for the worsening of $R$ and the goodness of fit for both alternatives.) The results are a strong indication that the first alternative is correct, all the more since it was the second alternative that had been refined to this point (because a simultaneous change of the signs of the indices of $\left|F_{h k l}\right|$ as well as of the atomic parameters $x, b_{12}$, and $b_{13}$ is equivalent to no change). The X-ray data thus indicate that the absolute configuration of the myronate ion is that represented by the parameters in Table 2 and the Figs. 1 and 5, which is in agreement with the configuration deduced on chemical grounds (see e.g. Kjaer, 1960, 1961).

\section{Table 2. Heavy-atom parameters and their standard deviations (in parentheses)}

All values have been multiplied by $10^{4}$. The anisotropic temperature factor is expressed in the form

$\exp \left[-\left(b_{11} h^{2}+b_{22} k^{2}+b_{33} l^{2}+b_{12} h k+b_{13} h l+b_{23} k l\right)\right]$.

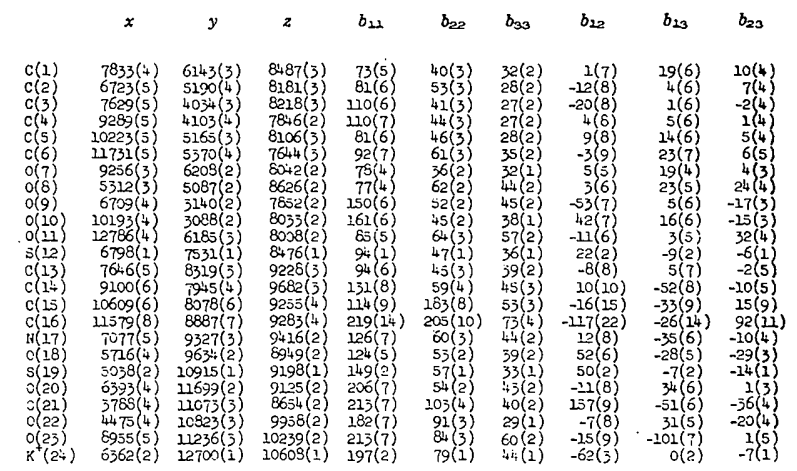

After adjustment of the scale factor, four final refinement cycles were undertaken, in which the anomalous dispersion corrections were included in the structure factors and the least-squares terms were rearranged 
in the earlier fashion. The final value of $R$ was 0.0560 and of the goodness of fit parameter 1.47. The final shifts for most of the parameters were less than 0.25 e.s.d., except that the temperature factor of $\mathrm{H}(17)$ shifted by more than 0.8 e.s.d. A total of 290 parameters were used in the least-squares fitting of the 1906 reflections that were given non-zero weights. Tables 2 and 3 give all the atomic parameters. The extinction parameter has the value $(2 \cdot 0 \pm 0 \cdot 2) \times 10^{-6}$. The calculated and observed structure factors are shown in Table 4.

Table 3. Parameters, and standard deviations, of the hydrogen atoms

Values for the coordinates have been multiplied by $10^{3}$. The temperature factors are in the form $\exp \left(-B \sin ^{2} \theta / \lambda^{2}\right)$. Atom $\mathrm{O}(23)$ is the oxygen atom of the $\mathrm{H}_{2} \mathrm{O}$ molecule.

\begin{tabular}{|c|c|c|c|c|c|}
\hline $\begin{array}{l}\text { Aton } \\
\text { numbe }\end{array}$ & $\begin{array}{c}\text { Atom } \\
\text { bonded } \\
\text { to }\end{array}$ & $x\left(\sigma_{x}\right)$ & $y\left(\sigma_{y}\right)$ & $z\left(\sigma_{z}\right)$ & $B\left(\sigma_{B}\right)$ \\
\hline$H(1)$ & $C(1)$ & $808(4)$ & $600(3)$ & $894(2)$ & 2. \\
\hline $\mathrm{H}(2)$ & $c(2)$ & $646(5)$ & $540(3)$ & $781(2)$ & 2.2( \\
\hline $\mathrm{H}(3)$ & $c(3)$ & $788(5$ & $387(3)$ & $879(2)$ & $3.5(1$ \\
\hline $\mathrm{H}(4)$ & C(4 & $33(5$ & $416(3)$ & $730(2)$ & 2. \\
\hline $\mathrm{H}(5)$ & $C(5)$ & $1052(4)$ & $513(3)$ & $862(2)$ & 1. \\
\hline $\mathrm{H}(6)$ & $c(6)$ & $4(5)$ & $562(3)$ & $714(2)$ & 2. \\
\hline & $c(6)$ & 123716 & $471(4$ & $763(3)$ & \\
\hline $\mathrm{H}(8)$ & $0(8)$ & 46915 & $549(4$ & $848(3)$ & \\
\hline $\mathrm{H}(9)$ & $o(9)$ & $635(6)$ & $280(4)$ & $811(2)$ & 4. \\
\hline $\mathrm{H}(10)$ & $O(10)$ & $1016(5)$ & $281(3$ & $780(2)$ & \\
\hline $\mathrm{H}(1])$ & $O(11)$ & $1285(7)$ & $677(4$ & $775(3)$ & \\
\hline$H(12)$ & $c(14$ & & 715 & $982(2)$ & 4. \\
\hline II 73 & C(14 & $904(6)$ & 842 & $1016(3)$ & $5.6 i$ \\
\hline $\mathrm{H}(14$ & $C(15)$ & $1181(8)$ & $759(6)$ & $897(4)$ & 11.6( \\
\hline (15) & $C(16)$ & $1274(10)$ & $898(7)$ & $892(4)$ & 17. \\
\hline $\mathrm{H}(16)$ & $c(16)$ & $1081(13)$ & 94I(9) & $975(6)$ & \\
\hline $\mathrm{H}(17)$ & $O(23)$ & $940(6)$ & $1105(4)$ & $1047(3)$ & \\
\hline & $O(23)$ & 7) & $1086(5$ & $994(3)$ & \\
\hline
\end{tabular}

\section{Discussion}

Bonding distances and angles are shown in Fig. 2. These distances are based on the unit-cell dimensions measured with a new crystal (Table 1). Similar distances calculated with the same parameters but with the cell measurements of a radiation-damaged crystal differ from those shown by less than $0.005 \AA$, except for the distances $\mathrm{S}(19)-\mathrm{O}(21)$ and $\mathrm{S}(19)-\mathrm{O}(22)$ which change from 1.426 and 1.432 to 1.432 and $1.444 \AA$, respectively. No angles are changed by more than $0.5^{\circ}$. On the grounds of the formal e.s.d. values, the possible effects of changes in cell dimensions (which are small, the bonds being largely inclined relative to the $c$ axis), and the internal consistencies of chemically equivalent bond distances, we judge the interatomic distances shown in Fig. 2 to be accurate to about $0.01 \AA$ and the angles to $1-2^{\circ}$.

Fig. 3 represents the surroundings of atom $\mathrm{S}(12)$ while Fig. 4 shows the sulfate group and the neighborhood of the atoms $\mathrm{N}(17)$ and $\mathrm{C}(13)$. The near planarity of the grouping $\mathrm{S}(12), \mathrm{C}(13), \mathrm{C}(14), \mathrm{N}(17)$, and $\mathrm{O}(18)$ is shown in Table 5, which also contains data that indicate the close planarity of the vinyl group (excepting $\mathrm{H}(14)$, the significance of which is discussed later).

Information concerning the average plane of the puckered glucose six-ring and the distances of atoms from this plane is also given in Table 5. To describe the precise conformation of the glucose six-ring we follow Brown \& Levy (1963) in defining the conformation angle (called here $\varphi$ ) of a directed bond $\mathrm{C}(2) \rightarrow \mathrm{C}(3)$ in a sequence of bonded atoms $\mathrm{C}(1), \mathrm{C}(2), \mathrm{C}(3)$, and $\mathrm{C}(4)$ as the angle, measured counterclockwise, that the projection of the bond $\mathrm{C}(2) \rightarrow \mathrm{C}(1)$ onto a plane perpendicular to the bond $\mathrm{C}(2) \rightarrow \mathrm{C}(3)$ makes relative to the projection of the bond $\mathrm{C}(3) \rightarrow \mathrm{C}(4)$, when one

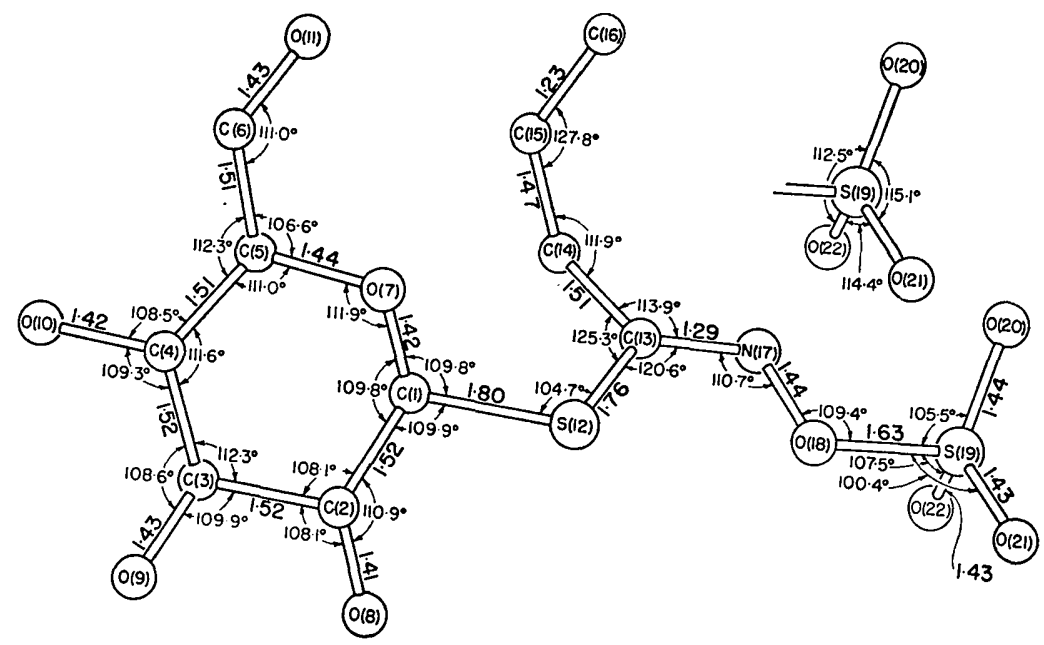

Fig. 2. Distances and angles in the myronate ion. 


\section{Table 4. Observed and calculated structure factors}

Within each group are given the values of $l, 10 F_{o}$, and $10 F_{c}$, and the phase angle in degrees. Reflections indicated with an asterisk were omitted from the least-squares refinement. A minus sign preceding $F_{o}$ signifies 'less than'; these reflections have been omitted from the refinement unless the value of $F_{c}$ exceeds the threshold value of $F_{0}$.

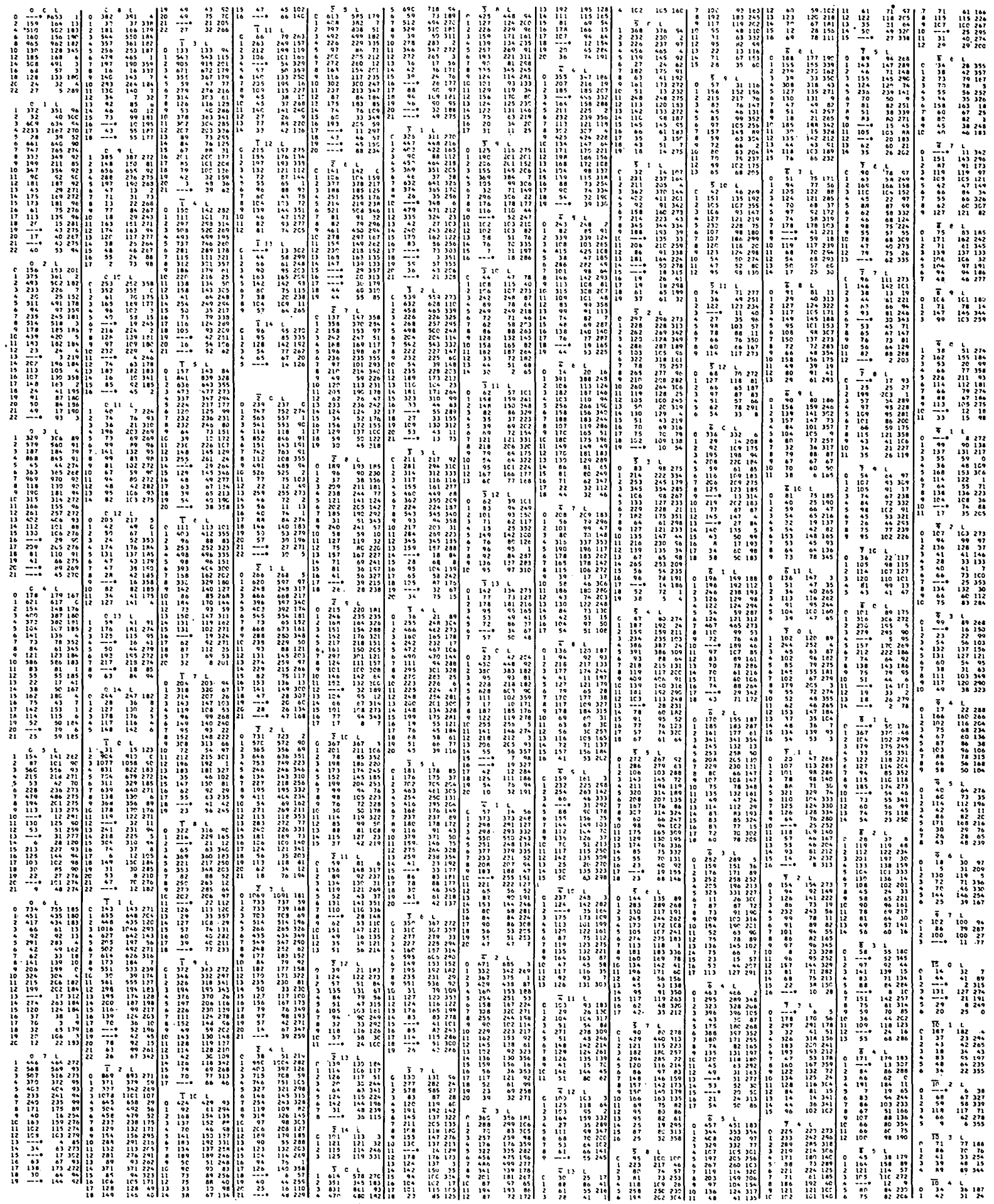




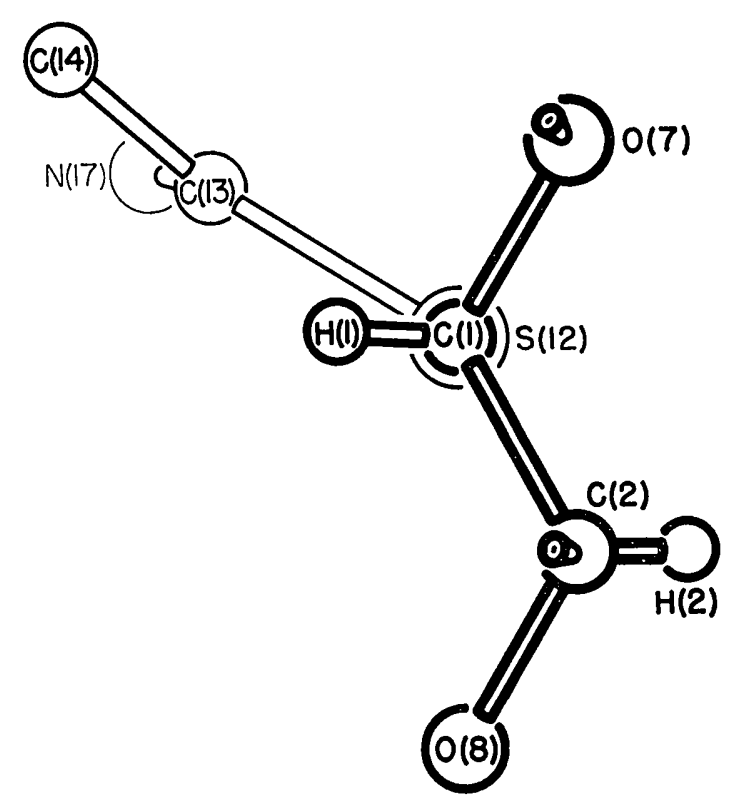

Fig. 3. Surroundings of the atom S(12). Atoms $C(2), C(1)$, and $\mathrm{O}(7)$ are part of the glucose ring and the bonds emerging from atoms $C(2)$ and $O(7)$ go to atoms $C(3)$ and $C(5)$ of that ring.

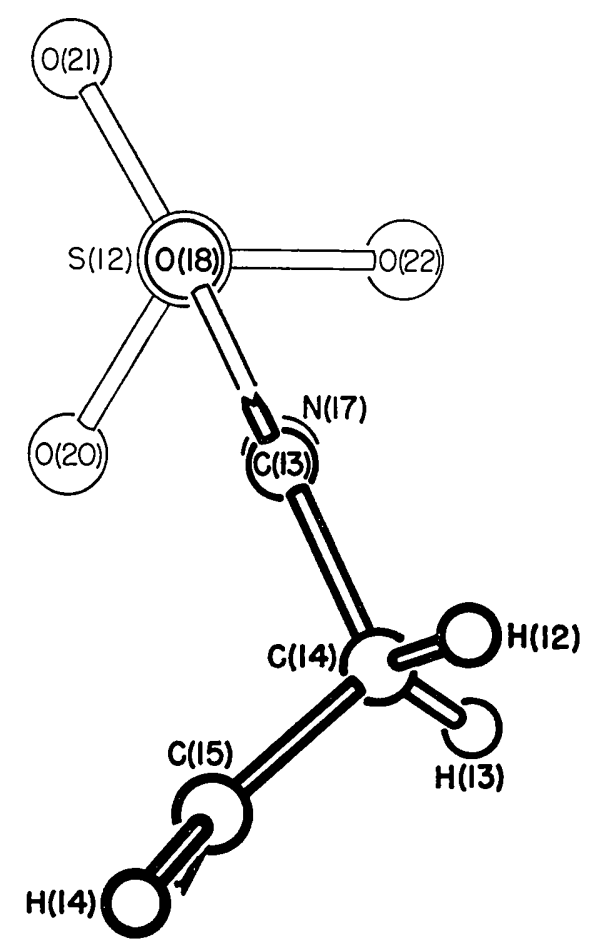

Fig. 4. The sulfate group and the surroundings of atoms $N(17)$ and $C(13)$. Note that the bonds $\mathrm{O}(18)-\mathrm{S}(12)$ and $\mathrm{C}(13)-\mathrm{N}(17)$ are nearly parallel and that the atoms attached to the atoms $N(17)$ and $C(13)$ are nearly coplanar. looks in the direction of the bond $\mathrm{C}(2) \rightarrow \mathrm{C}(3) . *$ In the glucose ring the conformation angles are $\mathrm{C}(1) \rightarrow \mathrm{C}(2)$, $+60.5^{\circ} ; \mathrm{C}(2) \rightarrow \mathrm{C}(3),-52 \cdot 2^{\circ} ; \mathrm{C}(3) \rightarrow \mathrm{C}(4),+48.4^{\circ}$; $\mathrm{C}(4) \rightarrow \mathrm{C}(5), \quad-50 \cdot 6^{\circ} ; \quad \mathrm{C}(5) \rightarrow \mathrm{O}(7), \quad+60 \cdot 6^{\circ}$; $\mathrm{O}(7) \rightarrow \mathrm{C}(1),-66 \cdot 4^{\circ}$.

Fig. 5 is a stereoscopic view of the contents of the asymmetric unit. The ellipsoids shown depict the thermal motions of all atoms other than hydrogen atoms. The abnormally large motions of the carbon atoms of the vinyl group, $\mathrm{C}(15)$ and $\mathrm{C}(16)$, are discussed later.

The packing of the myronate ions, water molecules, and potassium ions is shown in Fig.6, while Fig.7 shows the details of the environment of the potassium ions and Table 6 contains information about the hydrogen bonding in the crystal. On the whole the hydrogen bonding is normal, but there are several points of interest regarding it. One of them is that the glucose oxygen atom $\mathrm{O}(7)$ acts as acceptor to a hydrogen bond (line 3 of Table 6), which is most unusual for an oxygen atom in an ether-like linkage. Another is that the nitrogen atom $\mathrm{N}(17)$ acts as acceptor, forming a bond to a hydrogen atom $\mathrm{H}(18)$ of the water molecule. This may be the result of a residual negative charge on the nitrogen atom, caused by a partial delocalization of the $C(13)=N(17)$ double bond towards the sulfur atom $\mathrm{S}(12)$. The same hydrogen atom $\mathrm{H}(18)$ is also rather close to the oxygen atom $\mathrm{O}(20)$ of the sulfate group.

We finally wish to point towards a possible explanation of the abnormally large temperature ellipsoids of atoms $C(15)$ and $C(16)$ of the vinyl group, and to the fact that our final positional parameters of the hydrogen atom $H(14)$, attached to $C(15)$, place this atom outside the plane of the vinyl group by the relatively large distance of $0.4 \AA$. It turns out that atoms $C(15)$ and $\mathrm{C}(16)$ of a given molecule are only 3.5 and $3.6 \AA$ from atom $\mathrm{C}(14)$ of the molecule related to the first by an axis $2_{1}$ in the $x$ direction, and in a similar way atom $\mathrm{C}(14)$ of the original molecule is only 3.5 and $3.6 \AA$ from atoms $C(15)$ and $C(16)$ of a molecule related to the original molecule by the same screw axis, but on the other side of it. There is therefore the possibility of radiation-induced photopolymerization, involving the vinyl groups of neighboring molecules. Such a reaction in the solid might also account for the radiationinduced change of the unit-cell dimensions. The largest

* The sign of $\varphi$ can be defined more compactly and less transparently by stating that this sign is the same as that of the pseudo-scalar triple product $\left[\overrightarrow{\mathrm{C}_{1} \mathrm{C}_{2}} \cdot \overrightarrow{\mathrm{C}_{2} \mathrm{C}_{3}} \times \overrightarrow{\mathrm{C}_{3} \mathrm{C}_{4}}\right]$. In more detail, if unit vectors $n_{1}, n_{2}$ and $n_{3}$ parallel to the vectors $\overrightarrow{\mathrm{C}_{1} \mathrm{C}_{2}}$, $\overrightarrow{\mathrm{C}_{2} \mathrm{C}_{3}}$, and $\overrightarrow{\mathrm{C}}_{3} \mathrm{C}_{4}$ are introduced together with a torsion vector $\tau=\mathbf{n}_{2} \sin \varphi$ directed along the bond considered, with $\varphi$ as defined earlier, then $\tau \sin \left|\theta_{1}\right| \sin \left|\theta_{2}\right|=\left[-\mathbf{n}_{1} \times \mathbf{n}_{2}\right] \times\left[-\mathbf{n}_{2} \times \mathbf{n}_{3}\right]=$ $\mathbf{n}_{2}\left[\mathbf{n}_{1} \cdot \mathbf{n}_{2} \times \mathbf{n}_{3}\right]$ where $\left|\theta_{1}\right|$ and $\left|\theta_{2}\right|$ are the positive bond angles

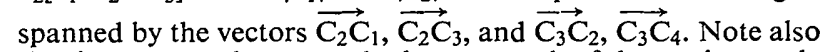
that it comes to the same whether we speak of the torsion angle of the bond $\mathrm{C}(2) \rightarrow \mathrm{C}(3)$ or of the bond $\mathrm{C}(3) \rightarrow \mathrm{C}(2)$, including the sign, because $\left.\overrightarrow{\left[\mathrm{C}_{4} \mathrm{C}_{3}\right.} \cdot \overrightarrow{\mathrm{C}_{3} \mathrm{C}_{2}} \times \overrightarrow{\mathrm{C}_{2} \mathrm{C}_{1}}\right]=$ $-\left[\overrightarrow{\mathrm{C}}_{3} \mathrm{C}_{4} \cdot \overrightarrow{\mathrm{C}}_{2} \mathrm{C}_{3} \times \overrightarrow{\mathrm{C}}_{1} \mathrm{C}_{2}\right]=\left[\overrightarrow{\mathrm{C}}_{1} \mathrm{C}_{2} \cdot \overrightarrow{\mathrm{C}}_{2} \mathrm{C}_{3} \times \overrightarrow{\mathrm{C}}_{3} \mathrm{C}_{4}\right]$. 
feature on our final difference map, a peak of 0.5 e. $\AA^{-3}$, was near the vinyl group, but gave no clear indication as to the mechanism of the proposed polymerization.

We thank Dr William H. Watson Jr for discussion and encouragement.

\section{References}

BOND, W. L. (1951). Rev. Sci. Instrum. 22, 344.

Brown, G. M. \& LeVy, H. A. (1963). Science, 141, 921.

CROMER, D. T. (1965). Acta Cryst. 18, 17.

Duchamp, D. J. (1964). Amer. Cryst. Assoc. Meeting, Bozeman, Montana, paper B-14, p. 29.

Table 5. Several planes of interest and the deviations of individual atoms from these planes

Direction cosines $q$ are relative to the unit-cell axes; $D$ is the origin-to-plane distance. Plane S(12), C(13), C(14), N(17), O(18)

\begin{tabular}{llrlr} 
& \multicolumn{4}{c}{ Deviations } \\
$q_{1}=-0.615$ & $S(12)$ & $-0.00 \AA$ & $C(1)$ & $0.20 \AA$ \\
$q_{2}=-0.454$ & $C(13)$ & 0.02 & $C(15)$ & -1.33 \\
$q_{3}=0.645$ & $C(14)$ & -0.01 & $S(19)$ & -0.04 \\
$D=2.34 \AA$ & $\mathrm{N}(17)$ & -0.00 & $\mathrm{H}(12)$ & 0.61 \\
& $\mathrm{O}(18)$ & -0.00 & $\mathrm{H}(13)$ & 0.32
\end{tabular}

Plane C(14), C(15), C(16)

\begin{tabular}{llcrr}
$q_{1}=0.499$ & \multicolumn{3}{c}{ Deviations } \\
$q_{2}=-0.471$ & $\mathrm{C}(13)$ & $-1.39 \AA$ & $\mathrm{H}(14)$ & $0.39 \AA$ \\
$q_{3}=0.728$ & $\mathrm{H}(12)$ & 0.58 & $\mathrm{H}(15)$ & -0.04 \\
$D=11.98 \AA$ & $\mathrm{H}(13)$ & 0.34 & $\mathrm{H}(16)$ & 0.00
\end{tabular}

Plane C(1), C(2), C(3), C(4), C(5), O(7)

\begin{tabular}{llrlr} 
& \multicolumn{4}{c}{ Deviations } \\
$q_{1}=0.196$ & $\mathrm{C}(1)$ & $0.28 \AA$ & $\mathrm{O}(8)$ & $0.31 \AA$ \\
$q_{2}=-0.173$ & $\mathrm{C}(2)$ & -0.24 & $\mathrm{O}(9)$ & -0.40 \\
$q_{3}=0.965$ & $\mathrm{C}(3)$ & 0.20 & $\mathrm{O}(10)$ & 0.49 \\
$D=14.32 \AA$ & $\mathrm{C}(4)$ & -0.18 & $\mathrm{~S}(12)$ & -0.18 \\
& $\mathrm{C}(5)$ & 0.21 & &
\end{tabular}

Table 6. Hydrogen-bonded interactions $X-\mathrm{H} \cdots Y^{\prime}$

The column labelled ' $x^{\prime}, y^{\prime}, z^{\prime}$ ' gives the position of the atom $Y^{\prime}$ in terms of the parameters of the same atom in the asymmetric unit that also contains the atoms $X$ and $\mathrm{H}$ listed in Tables 2 and 3 . In view of the low precision of the locations of the hydrogen atoms, the distances $X-\mathrm{H}$ and $\mathrm{H} \cdots Y$ given in this Table are much less reliable than the distances $X \cdots Y$. Atom $\mathrm{O}(23)$ is the oxygen atom of the $\mathrm{H}_{2} \mathrm{O}$ molecule.

\begin{tabular}{|c|c|c|c|c|c|c|c|c|}
\hline$X$ & $\mathbf{H}$ & $Y^{\prime}$ & \multicolumn{3}{|c|}{$x^{\prime}, y^{\prime}, z^{\prime}$} & $X-\mathbf{H}$ & $H \cdots Y$ & $X \cdots Y$ \\
\hline $\mathrm{O}(8)$ & $\mathrm{H}(8)$ & $O(11)$ & $x-1$ & $y$ & $z$ & 0.73 & 1.95 & 2.67 \\
\hline$O(9)$ & $H(9)$ & $O(20)$ & $x$ & $y-1$ & $z$ & 0.67 & $2 \cdot 20$ & $2 \cdot 81$ \\
\hline$O(10)$ & $H(10)$ & $O(7)$ & $2-x$ & $y-\frac{1}{2}$ & $\frac{3}{2}-z$ & 0.52 & $2 \cdot 42$ & $2 \cdot 91$ \\
\hline$O(11)$ & $H(11)$ & $O(9)$ & $2-x$ & $\frac{1}{2}+y$ & $\frac{\frac{3}{2}}{2}-z$ & 0.81 & 1.94 & $2 \cdot 74$ \\
\hline$O(23)$ & $\mathrm{H}(17)$ & $O(8)$ & $\frac{1}{2}+x$ & $\frac{3}{2}-y$ & $2-z$ & 0.59 & $2 \cdot 20$ & $2 \cdot 76$ \\
\hline$O(23)$ & $\mathrm{H}(18)$ & $N(17)$ & $x$ & $y$ & $z$ & 0.87 & $2 \cdot 23$ & 3.05 \\
\hline$O(23)$ & $\mathrm{H}(18)$ & $O(20)$ & $x$ & $y$ & $z$ & 0.87 & $2 \cdot 35$ & $2 \cdot 95$ \\
\hline
\end{tabular}
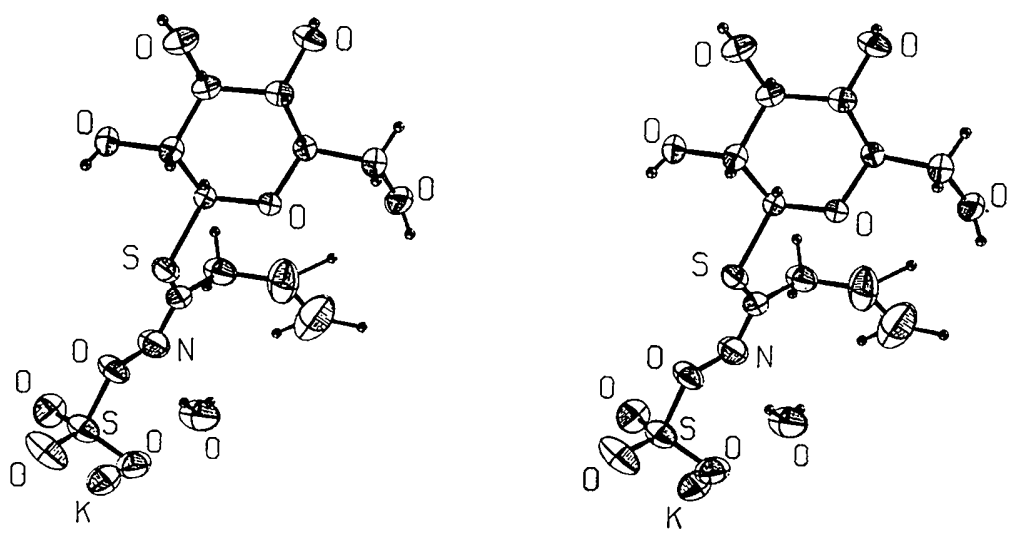

Fig. 5. Stereoscopic figures showing temperature ellipsoids. 


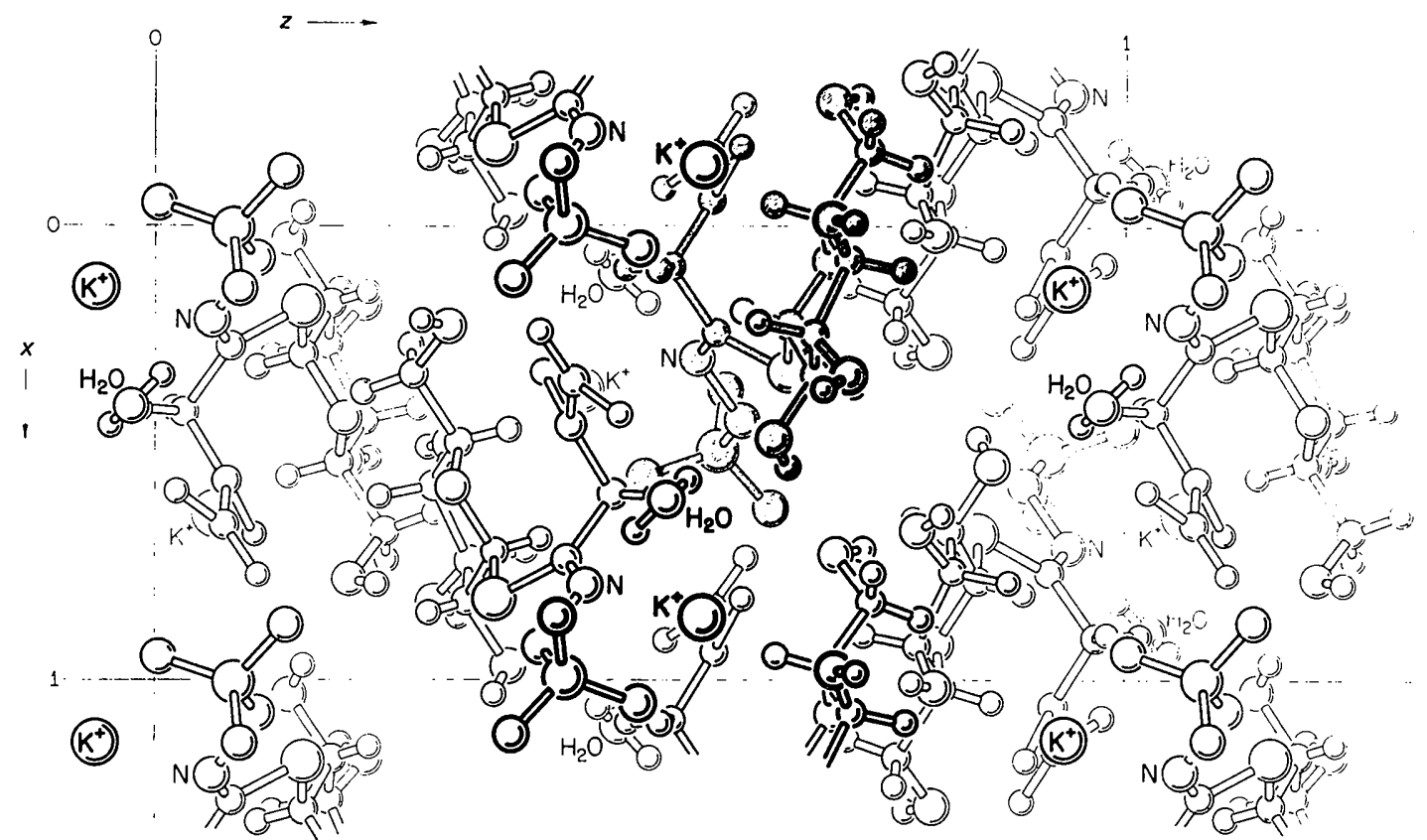

Fig.6. Packing drawing. The $y$ axis points down. One complete myronate ion has been shaded grey.

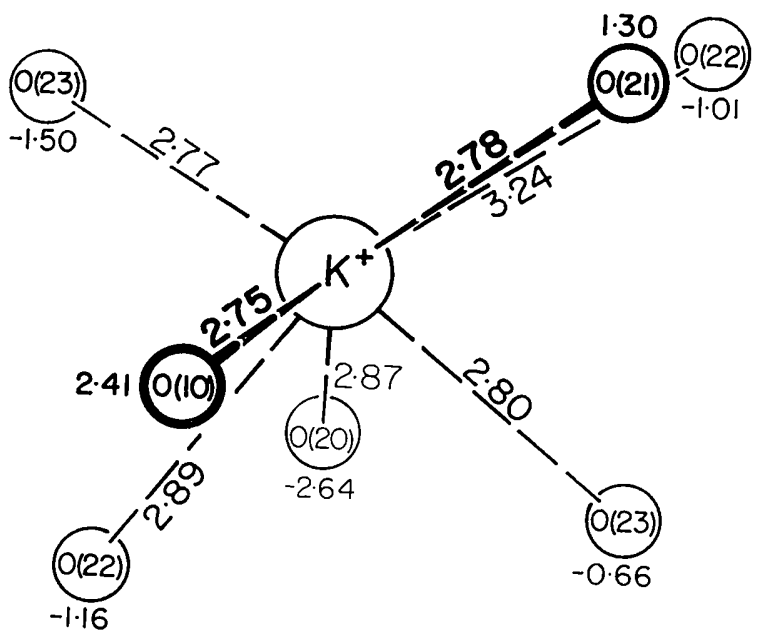

Fig. 7. The environment of the potassium ion.
Ettlinger, M. G. \& Lundeen, A. J. (1956). J. Amer. Chem. Soc. 78, 4172 .

Ettlinger, M. G. \& Lundeen A. J. (1957). J. Amer. Chem. Soc. 79, 1764.

Ettlinger, M. G., Dateo, G. P. JR, Harrison, B. W., Mabry, T. J. \& ThOMPSON, C. P. (1961). Proc. U.S. Nat. Acad. Sci. 47, 1875.

International Tables for X-ray Crystallography (1962). Vol. III, pp. 202-203. Birmingham: Kynoch Press.

KJAER, A. (1960). In Fortschritte der Chemie Organischer Naturstoffe, Ed. L. Zechmeister, Vol. 18, p. 122. Wien: Springer.

KJAER, A. (1961). In Organic Sulphur Compounds, Ed. N. Kharash, Vol. 1, p. 413. Oxford, New York: Pergamon Press.

Larson, A. C. (1967). Acta Cryst. 23, 664.

Stewart, R. F., Davidson, G. R. \& Simpson, W. T. (1965). J. Chem. Phys. 42, 3175.

WASER, J. (1963). Acta Cryst. 16, 1091.

WASER, J. \& WATSON, W. H. (1963). Nature, Lond. 198, 1297.

Zachariasen, W. H. (1963). Acta Cryst. 16, 1139. 